\title{
Key Success Factors for Developing Competitive Intelligence in Organisation
}

\author{
Wadie Nasri ${ }^{1}$ and Mohamed Zarai ${ }^{2}$ \\ ${ }^{I}$ Higher Institute of Management, University of Gabes, Tunisia \\ ${ }^{2}$ Faculty of Business Administration, Majmaah University, Saudi Arabia
}

\begin{abstract}
The purpose of this paper is twofold. First, to understand Competitive Intelligence (CI) and report the process that is commonly used to create and maintain a CI program in organizations. And second, to provide key success factors in developing a functional intelligence program for an organization. The paper presents a review of the literature on CI process to collect and analyze competitive information within organizations in order to identify key success factors in developing a functional intelligence program for an organization. Five success factors can be defined as an item related to CI process: management support and understanding, focus and CI effort, location of CI function, CI personal, and product. The paper provides executive decision makers and strategic managers a better understanding of what CI process and appropriate to the decisions they must to develop a functional intelligence program for an organization.
\end{abstract}

Key Words: Competitive Intelligence, IC process and effort, function, personal, product, organisations

\section{Introduction}

The rapid environments changes pose important constraints and contingencies for organizations, and their competitiveness depends on their ability to monitor and adapt their strategies based on information acquired through environmental scanning activities (Boyd \& Fulk, 1996). Competitive Intelligence (CI) is the process by which organizations gather and use information about products, customers, and competitors, for their short and long term strategic planning (Ettorre, 1995).

CI is an important source of information for business planning and other activities because it provides information about present and future behavior of competitors and the general business environment (Vedder \& Guynes, 2002). Integrating knowledge management and CI encourages their use, improves their quality and allows the firm to respond more rapidly to changing business conditions (Senge, 1990). It is the first step guiding the planning and redesign of processes, products, and organization structure (Gimaraes, 2000).

Companies with using $\mathrm{CI}$ and analysis of competitor's strengths and weaknesses are able to predict opportunities of market development and having better performance rather than competitors (Britt, 2006). CI examples include analysis of the manufacturing or service capabilities of the competitors; analysis of alliances and/or joint ventures entered into by competitors; the competitor's future plans and strategies for specific markets, or product lines; reasons behind changes in the corporate or business unit strategy, etc. (Britt, 2006).

$\mathrm{CI}$ is an art of collecting, processing and storing information to be made available to people at all levels of the firm to help shape its future and protect it against current competitive threat: it should be legal and respect codes of ethics: it involves a transfer of knowledge from the environment to the organisation within established rules (Rouach \& Santi, 2001).

The aim of CI is management and reduction of risk, create useful knowledge, safety information and use of shared information (Priporas et al, 2005). Organizations that use a CI program, has better understanding of the competitive landscape (Vedder et al, 2002), and with moving toward a wise strategies, they develop programs to increase their competitive advantage (Wright \& Calof, 2006). Piercy et al, (1998), also states, that organizations which have intelligent employees are able to make competitive advantage through innovation better than others. Consequently, many organizations, are initiating their own CI services to advise their decision makers. Without a proper intelligence process and structure, it is difficult to develop intelligence.

The purpose of this survey research is twofold. First, to understand CI and report the process that is commonly used to create and maintain a CI program in organizations. And second, to identify key success factors in developing a functional intelligence program for an organization. The rest of the paper is organized as follows: section 2 explains a clear understanding of $\mathrm{CI}$ and its benefits. Section 3 
explains the process commonly used in CI. Section 4 describes the key success factors in developing a functional intelligence program for an organization. Section 5 concludes the paper.

\section{What is Competitive Intelligence?}

The Society of Competitive Intelligence Professionals (SCIP, 2008) defines CI as a systematic and ethical process for gathering, analysing and managing external information that can affect the company's plans, decisions and operations. CI means a systematic process initiated by organizations in order to gather and analyze information about competitors and the general socio-political and economic environment of the firm (Colakoglu, 2011).

It is conceptualized as a process of monitoring the competitive environment, with a goal to provide actionable intelligence that will provide a competitive edge to the organization (Kahaner, 1998). Fleisher (2001) prefers to consider the process of CI in which organizations capture information on competitors and their environment and applies it in their decision making process and planning with the purpose of improving the performance of the business. CI techniques systematically and ethically gather, analyze and disseminate external information that can assist with organizational decision-making and the design of strategic and operational plans (SCIP, 2008).

The most common benefit of CI however is its ability to build information profiles that helps a company identify its competitor's strengths, weaknesses, strategies, objectives, market positioning and likely reaction patterns (Ranjit, 2008); provide the basis for continuous improvement (Babbar \& Rai, 1993); shed light on competitor strategies (Westervelt, 1996); improve speed to markets and supporting rapid globalization (Ettorre, 1995); improve the likelihood of company survival (Westervelt, 1996); increase business volume (Darling, 1996); providing better customer assessment (Darling, 1996); and to aide in the understanding of external influences (Sawka et al, 1996).

Competitive intelligence (CI) can help formulate strategy through an understanding of the company's industry, the company itself, and its competitors. CI therefore is the essence of strategic business analysis. It can also help identify areas of improvement as well as risks and opportunities (Ranjit, 2008). By using CI firms may reach better performance in fallowing areas -Acquisition of new business

-Retention of existing business

-Improvements in sales-force performance and morale.

-Identification of new business opportunities.

-Sharing of ideas.

-Improved ability to anticipate surprises.

-Improving managers' analytical skills.
-Integrating diverse ideas.

-Enhancing organization's competitiveness.

-Predicting, with a high level of trust, business environment's evolutions, competitors' actions, customers' requirements, even influences generated by political changes.

-Providing a better and better support for strategic decision making process (Anica-Popa \& Cucui, 2009).

$\mathrm{CI}$ is frequently misunderstood as it's a sort of business espionage. The reason of this confusion is they both have common activities. But espionage is unlawful and unethical while competitive intelligence is legal and associated with a detailed code of ethics (Richardson \& Luchsinger, 2007).

\section{Competitive Intelligence process}

The CI process is often cited in literature as a fivephase process, consisting of formal and informal activities: planning and focus, data and information collection, analysis, dissemination and feedback of intelligence (Kahaner, 1998).

Planning and focus - In this phase the company's defines their needs in terms of what information is needed? Why is it needed? When is it due? - Effective intelligence processes do not attempt to collect all possible information or research everything related to a subject (Gilad \& Gilad, 1985; Herring, 1998). CI should only focus on those issues of highest importance to senior management (Gilad, 1989; Gilad and Gilad, 1985; Herring, 1998; Montgomery and Weinberg, 1979; Porter, 1980). It involves working with decision makers to discover their intelligence needs and then translating those needs into their specific intelligence requirements or "key intelligence topics" (KITs) (Weiss, 2002). This phase is required to allow the necessary resources for the CI process. Herring (1998) and Gilad (1989) have emphasized the importance of planning and focus for the intelligence effort.

Collection - In this phase the organization's needs must be translated into specific elements of information that will be required. A list of questions and selected potential sources should be prepared in advance in order to make collection activities more targeted and effective. Information is collected from a variety of different sources. These include both primary and secondary sources.

Primary data comes straight from the source, your competition or people who know about your competition (Richard, 2007). Primary sources may be industry experts (e.g., analysts and consultants), as well as customers, suppliers and key staff members within such departments as corporate communications and investor relations. According to Kahaner (1998), author of CI, the single best source of CI is your sales 
force. Similarly, the people in your organization who talk to suppliers and truckers often can unearth valuable competitive information. Other good primary sources include:

-Speeches by CEOs and others in top management. -Articles, research papers, or books authored by employees.

-Company Web site content.

-Patents and commercial registry findings.

-Surveys and interviews.

-Remote sensing (such as from cameras or satellite imagery).

-Building permits.

-Uniform Commercial Code (UCC) registrations (Richard, 2007).

Secondary data sources can include various databases and print publications, such as analysts' reports, government publications, industry newsletters, annual reports, executives' speeches, technical reports, patent reports and publications generated by competitors. External sources do not have to be published; in fact, most managers get much of their information from word-of mouth through a personal network of contacts. Obviously, the Internet comes heavily into play here (Richard, 2007). Internet has vastly simplified the task of discovering information about competitors and industry trends from:

-Newspapers, business magazines, and other print media.

-Electronic sources.

-Analysts' reports and expert opinions.

-Books about the industry or company.

-Published commentary and observations.

-Legal briefs and filings.

-General blogs.

-Employee blogs

The choice of a particular source is directly related to the type of data or information required; such factors as ease of access ease of processing the source, cost, availability, quantity and quality of information will also probably impact on selection (Wanderley 1999). Collection is also about ensuring that the information and sources of information are tested for reliability and credibility.

Analysis - It is an essential step, which includes analysis of collected data to identify patterns, relationships, or anomalies in it. It involves interpreting and translating the collected raw data into "actionable intelligence" (Miller, 2001). Many practitioners believe that this is where "true" intelligence is created, that is converting information into usable intelligence on which strategic and tactical decisions may be made (Gilad, 1989; Gilad \& Gilad, 1985; Kahaner, 1996; Calof and Miller, 1997; Herring, 1998). Professionals evaluate the data to determine the validity of their assumptions as well as the probability of the forthcoming impacts.

A number of analytical tools and models are available to place the collected data within a useful context for strategic decision making. Fleischer and Bensoussan (2003) and Gray (2010) have identified several strategic analytical techniques including

-SWOT (Strengths, Weaknesses, Opportunities, and Threats) analysis

-Competitor profiles

-Environmental scanning

-Modeling, PEST

-Industry analysis (Porters Five Forces Model)

-Financial analysis

-BCG growth/share portfolio matrix

-GE Business screen matrix

-Scenarios

-War gaming

-Value chain analysis

Each of these analytical techniques involves mapping collected information to predefined matrices or information categories to address specific strategic decisions. Each is good in some areas and flawed in others. In addition, they must be able to support the quick reaching of conclusions in the face of new information.

Communication and feedback - The results of the intelligence process need to be communicated to the appropriate decision-makers within the firm in a format that is easily understood (Miller, 2001). There are several ways of presenting and disseminating competitive intelligence throughout a firm. Intelligence communication can take place via ad hoc reports, alerts, e-mails, presentations, news briefs, competitor files and special memos (Fleisher, 2001). Some companies hold periodic competitive debriefings for senior management in order to discuss the firm's principal competitors, their performance, their possible actions and the implications for the firm. Feedback activities involve measuring the impact of the intelligence that was provided to the decision makers.

Planning and focus, collection, analysis and communication and feedback are interrelated and therefore the success of the one will determine the success of the other (Straus \& Toit, 2010). Several studies indicate that the generally accepted norm for the CI cycle includes the constructs of planning and focus, collection, analysis, communication, process and structure, and organisational awareness and culture (Viviers et al. , 2005; Viviers \& Saayman, 2004). Intelligence requires appropriate policies, procedures, and a formal or informal infrastructure to enable employees to contribute effectively to the CI system as well as to gain benefits from the CI process are considered highly desirable. To utilize its CI efforts successfully, there needs to be an appropriate 
organizational awareness of intelligence and a culture of competitiveness. Every organization implements the process differently, with specific components being assigned to individual members of an intelligence team or with the entire process being outsourced to a research firm or even to a single individual (Miller, 1996).

\section{Success Factors to Promote Competitive Intelligence}

There are five distinct success factors to be addressed when developing an effective intelligence program:

-Management support and understanding

-Focus and CI effort

-Location of CI function

-CI personal

-CI product

\section{Management support and understanding}

First, managers must recognize the importance of CI, by suggesting that it is the process by which organizations gather and use information about products, customers, and competitors to enhance the tactical and strategic decision-making process. This is evidence of the fact that $\mathrm{CI}$ is an important tool in the development of strategy in the organisations. In order to effectively utilize information in a manner desired by organizations, it is crucial that all employees understand issues such as why information is needed (for what purpose), how it is acquired (process), what kind of information is used, and where it is located.

\section{Focus and Competitive Intelligence effort}

There are five generic focuses that can be developed to elaborate CI programs (Prescott, 1999):

-A focus on early warning centers on identifying opportunities and threats in the before they become obvious to all industry players. The primary efforts of this focus center on how the firm should position itself in light of a potential opportunity or threat.

-A second focus is providing support for strategic decision making. These CI activities are designed to bring information and analysis to bear on important strategic thrusts.

-A third potential focus area, tactical decision making, emphasizes the day-to-day operations of a business. When CI is linked to the sales function, we often see a tactical focus.

-The fourth potential CI program focus would be competitive monitoring and assessment. In this situation, developing a deep understanding of competitors strategic and tactical intent and how to position the firm receives central attention.
-The fifth focus area is assistance with the strategic planning process of the organization. CI supporting this focal area centers on the collection and analysis of information that is an essential input into the design and implementation of strategic plans.

\section{Location of Competitive Intelligence function}

One of the important aspects of CI is communicating critical information to senior management that assists them in strategic decision-making. Therefore, the location of CI within the firm and its importance within the firm are critical. A recent study by Saayman et al, (2008) argues that the location of the CI unit has a significant impact on its efficacy. The location of the CI function is very important for a firm to fully leverage its effectiveness (Fuld, 1991). For maximum efficiency and power, the CI unit should be placed high enough in the organization so people respect it and see that it has a senior champion. However, it should also be accessible by everyone in the company and not be part of any one division as previously noted (Kahanner, 1998). CI unit can actively participate in introducing a competitive intelligence process in several ways:

-Identifying the need for a new or improved CI process;

-Educating top management and other senior managers about that need;

-Developing a plan along with cross-functional team members for designing, developing and implementing the new, improved competitive intelligence practice, including its underlying architectures;

-Identifying the appropriate tools and techniques for conducting competitor analysis;

-Providing financial input, analysis and expertise to the CI effort;

-Contributing to and using CI in target costing;

- Ensuring that the CI efforts are tied to the firm's goals, strategies, objectives and internal processes, as appropriate; and,

- Continually assessing the new, improved CI process and its implications for the organization, and continually improving the process.

CI function, like other function, has a variety of needs that must be met in order for intelligence to add value to the enterprise. These needs fall into five broad categories: access to decision-making; visibility; links to other parts of the enterprise; funding; and nurturing (Du Toit \& Muller, 2004).

CI units must be located so that they are in a position to support decision making by providing competitive insights, discussing alternatives and compelling action. CI must be as close to the decision maker as possible (Miller, 2000). Intelligence units should be highly visible components of corporate organizations. Intelligence units should be located 
organizationally so that they have strong links to other parts of the enterprise. Intelligence functions must be able to interact with other corporate components, for example sales and marketing, planning, purchasing and manufacturing (Du Toit \& Muller, 2004). Intelligence units that are to have any recognizable impact on corporate decision-making and competitiveness must have adequate staff, technology and other support (Miller, 2000).

\section{Competitive Intelligence personal}

To be effective, CI must reach the right people within the organization, and they must be willing to act on it and contribute towards CI. A variety of disciplines can be represented: marketing and sales, production and distribution, product development, finance and accounting. They must be capable of carrying out a variety of basic intelligence activities in a professional and proficient manner (Herring 1997). Prescott and Miller (2001) state that all employees can be trained to provide information to the CI group and that they are most likely to do so if they receive information in return to enable them to make valuable decisions. For example, marketing, sales and service staff are always aware of market behavior and trends, and of how competitors are creating them or usually responding to them. Salespeople are more than likely dealing with more than one organization, smaller organizations will not only be able to find out about changes in their supplier industries but also will be able to obtain information about what their competitors are doing. Although training is an additional construct to the CI process, it is clear that training contributes to the success of each phase in the CI cycle (Strauss \& Du Toit, 2010).

Embedding competitive intelligence necessitates considerable training throughout the organization. Employees need to know the rationale for the program. They need to perceive the usefulness of the competitive information they encounter. Finally, every employee must be motivated to become active in the program. Employees need education about possible sources of information that exist and about how to communicate in order to make the process work. A good intelligence program works only if everybody participates (Strauss \& Du Toit, 2010):

- Incentives - without incentives to provide a personal benefit, employees lack motivation to join the intelligence effort. Many companies motivate their employees to contribute by simply feeding back information through newsletters, e-mail or competitor information bulletin boards. Other firms give awards to employees who have contributed vital market and competitor information to managers.
- Awareness - even in high-morale organizations whose employees are happy to contribute vital information to management, individuals need to know what information is important and who needs it. Firms raise employee awareness in many ways. For example, Xerox's copier group constantly "broadcasts" competitor information throughout the organization via bulletin boards and displays. In one long corridor, for example, the Competitive Assessment Team posts competitors' newspaper advertisements to raise awareness of competing products, features and prices.

\section{Competitive Intelligence product}

Fleisher (2002) prefers to consider the process of CI in which organizations capture information on competitors and their environment and applies it in their decision making process and planning with the purpose of improving the performance of the business.

The value of the intelligence, produced through a CI program, can possibly be measured across one or more of the following attributes (Ranjit, 2007):

- Accuracy - all sources and data must be evaluated for the possibility of technical error or misperception;

- objectivity;

- Usability - must be in a form that facilitates ready comprehension and immediate application;

- Relevance - its applicability to a decision maker's requirements, with potential consequences and significance of the information made explicit to the decision maker's circumstances;

- Readiness - CI systems must be responsive to the existing and contingent intelligence requirements of decision makers for all levels of the organization; and - Timeliness - intelligence must be delivered while the content is still actionable under the decision maker's circumstances.

\section{Conclusion}

This paper has identified four different processes within intelligence: planning/focus, collection, analysis and communication, with process/structure and culture/awareness/attitude being undeniable influencers of success. The planning and focus phase concentrates on the identification of needs in order to collect all relevant information, which is the second phase. In the third phase all collected information must be verified to determine rationality and factuality. This information is then communicated in an appropriate way to the relevant parties. The fifth phase requires the appropriate policies and procedures to be in place for CI to make a positive contribution to the organisation. There are five distinct success factors to be addressed when developing an effective 
intelligence program on organisation: management support and understanding, focus and CI effort, location of CI function, CI personal, and CI product.

The study provides executive decision makers and strategic managers a better understanding of what CI process and appropriate to the decisions they must to develop a functional intelligence program for an organization. The findings of this study may not be generalisable without further empirical testing. Further research should explore other concepts that play an important role in developing CI in organisation.

\section{References}

Anica-Popa, I. \& Cucui G. (2009). A framework for enhancing competitive intelligence capabilities using decision support system based on web mining techniques, International Journal of Computers Communications and Control, IV (2009),. 4, 326-334.

Babbar, S., \& Rai, A. (1993). Competitive intelligence for international business, Long Range Planning, 26(3), 103-113.

Boyd B.K. \& Fulk J. (1996). Executive scanning and perceived uncertainty: A multidimensional model, Journal of Management, 22(1), 1-21.

Britt, P. (2006). The new competitive intelligence: raising the confidence quotient, KMWorld, November/December, 10-11.

Calof, J.L. \& Miller, J. (1997). The status of CI across the globe, Proceedings of the 12th Annual Conference of the Society of Competitive Intelligence Professionals, Alexandria, VA,

Colakoglu, T. (2011). The problematic of competitive intelligence: How to evaluate and develop competitive intelligence, Procedia Social and Behavioral Sciences, 24, 1615- 1623

Darling, M. S. (1996). Building the knowledge organization, Business Quarterly. 61(2), 61-66.

Du Toit, A.S.A. \& Muller, M. L. (2004). Organizational structure of competitive intelligence activities: a South African case study, South African Journal of Information Management, 6(3).

Etorre B. (1995), Managing competitive intelligence, Management Review, Oct 1995, 84(10), 15-19.

Fleisher, C.S. (2001). An introduction to the management and practices of competitive intelligence (CI), in Fleisher,C.G. and Blenkhorn, D.L. (Eds), Managing Frontiers in Competitive Intelligence, Quorum Books, Westport, CT, 3-18.

Fuld, L.M. (1991). A recipe for business intelligence success, Journal of Business Strategy, 12(1), 12-17.

Gilad, B. (1989). The role of organized competitive intelligence in corporate strategy, Columbia Journal of World Business, 24 (4), 29-36.

Gilad, B. \& Gilad, T. (1985). A systems approach to business intelligence, Business Horizons, 28(5), 65-70.

Gray P. (2010). Competitive intelligence, Business Intelligence Journal, 15, 4, 31-37.

Guimares, T. (2000). The impact of competitive intelligence and IS support is changing small business organizations, Logistics Information Management, 13(3), 117-25.

Herring, J. (1998). What is intelligence analysis?", Competitive Intelligence Magazine, 1(2), 13-16.

Kahaner, L. (1998). Competitive intelligence: How to gather, analyze and use information to move your business to the top. Touchstone, New York, NY.

Miller J.P. (1996). Information science and competitive intelligence: Possible collaborators?, American Society for Information Science. Bulletin of the American Society for Information Science, 23(1), 11-13.

Miller, S.H. (2001). Competitive intelligence-An overview, Society of Competitive Intelligence Professionals.
Montgomery, D.B. \& Weinberg, C.B. (1979). Toward strategic intelligence systems, Journal of Marketing, 43(4),41-52.

Peter R. J. T. \& Yang-I. L. (2008). A strategic marketing intelligence and multi-organisational resilience framework, European Journal of Marketing, 42(7/8),731-745.

Piercy, N.F., Kaleka, A. \& Katsikeas, C.S. (1998). Source of competitive advantage in high performance exporting companies, Journal of World Business, 33 (4), 378-93.

Porter, M.E. (1980). Competitive strategy: Techniques of analyzing industries and competitors, The Free Press, New York, NY.. 213-23.

Prescott J. E., (1999). The evolution of competitive intelligence: designing a process for action, Proposal Management, Spring, 37-52.

Priporac, C.V., Gastoris, L. \& Zacharis, V. (2005). Competitive intelligence activity: Evidence from Greece, Marketing Intelligence \& Planning, 23(7), 659-69.

Ranjit B. (2008). Competitive intelligence process and tools for intelligence analysis, Industrial Management and Data Systems, 108(4),510-528.

Richard L. W. (2007). Competitive intelligence: the new supply chain edge, Supply Chain Management Review, 11(1),18-27.

Richardson, L. \& Luchsinger, V. (2004). International pharmaceuticals industry: The new marketing paradigm in the us and unresolved issues of public policy, Journal of American Academy of Business, 5(1/2), 21-26.

Rouach, D. \& Santi, P. (2001). Competitive intelligence adds value: five intelligence attitudes, European Management Journal, 19, (5), 552-559.

Saayman, A., Pienaar, J., de Pelsmacker, P. J., Viviers, W., Cuyvers, L. Muller, M-L. \& Jegers, M. (2008). Competitive intelligence: Construct exploration, validation and equivalence, Aslib Proceedings, New Information Perspectives, 60(4), 383-411

Sawka, K.A., Francis, D.B. \& Herring, J.P. (1996). Evaluating business intelligence systems: How does your company rate?, Competitive Intelligence Review, 6 (4), 225.

Senge, P. M. (1990). The fifth discipline: The art and practice of the learning organization,' New York: Doubleday.

Society of Competitive Intelligence Professionals (SCIP). (2008). Society of competitive intelligence professionals, retrieved from: www.scip.org/content.cfm?itemnumber=2226\&nav Item Number $=2227$

Strauss, A.C. \& Du Toit, A.S.A. (2010). Skills shortages and competitiveness in South Africa: The need for competitive intelligence skills, Journal of Contemporary Management, 7: 307-324.

Vedder, R.G. \& Guynes, C.S. (2002). Guynes CIOS' perspectives on competitive intelligence, Information Systems Management, Fall, 49-55.

Viviers, W., Saayman, A. \& Muller, M. (2005). Enhancing a competitive intelligence culture in South Africa, International Journal of Social Economics, 32(7), 576-89.

Viviers, W., Saayman, A. \& Muller, M. (2005). Enhancing a competitive intelligence culture in South Africa, International Journal of Social Economics, 32(7), 576-89.

Wanderley, A. V. M. (1999). Um instrumento de macropolítica de informação: Concepção de um sistema de inteligência de negócios para gestão de investimentos de engenharia, Ciência da Informação, 28, 190-199.

Weiss, A. (2002). A brief guide to competitive intelligence: how to gather and use information on competitors, Business Information Review, 19(2), 39-47.

Westervelt, R. (1996). Gaining an edge: Competitive intelligence takes off', Chemical Week, 158(25), 29-31.

Wright, S. \& Calof, J. L. (2006). The quest for competitive, business and marketing intelligence: A country comparison of current practices, European Journal of Marketing. 40(5-6), 453-465

Wright, S., Pickton, D.W. \& Callow, J. (2002). Competitive intelligence in UK firms: a typology, Marketing Intelligence \& Planning, 20(6), 349-60. 